\title{
Rheological study of the effect of calcium surface-modified bentonite on an oil-based drilling fluid
}

\author{
R. P. Silva ${ }^{1}$, V. C. Santanna ${ }^{1}$, D. M. A. Melo ${ }^{2}$ \& A. L. Medeiros ${ }^{2}$ \\ ${ }^{1}$ Department of Petroleum Engineering, \\ Federal University of Rio Grande do Norte, Brazil \\ ${ }^{2}$ Department of Engineering Materials, \\ Federal University of Rio Grande do Norte, Brazil
}

\begin{abstract}
Due to the great challenges encountered in drilling wells, there is a need to develop fluids with appropriate properties that are able to meet all requirements of the drilling properties. Bentonite clays have economic importance by presenting a wide range of industrial applications. Bentonite can be used as a viscosity controlling agent for drilling fluid so as to allow greater efficiency in the transport of rock fragments to the surface. Regarding its thixotropic properties, bentonite clay allows the suspension to assume a gelatinous structure when at rest. This study aims to observe the rheological behavior of cationic surface-modified bentonite in drilling oil fluids. The results show that the clay dispersions have an oil-base Bingham and thixotropic behavior, which show potential as viscosifying agents for drilling fluids.

Keywords: organophilic clays, non-aqueous fluids, drilling.
\end{abstract}

\section{Introduction}

Drilling fluids, also called sludge, are indispensable for the drilling of oil wells industry (Amorim [2]). The main functions of fluids during the drilling operations are as follows: remove the debris generated by the drill bit, cool and clean the drill, and stabilize the walls of the well to prevent its collapse [7].

Drilling fluids consist of a continuous liquid phase and are chemically treated so as to adapt their properties to the drilling operations (Souza Santos [7]; Amorim [1]). Their main properties are density, viscosity, homogeneity, reactivity and salinity. 
Regarding the liquid dispersing medium, fluids can be of two types: waterbased fluids and non-aqueous fluids. The water-based fluids mainly comprise water and bentonite clay type, other substances are added to the fluid to get the desired properties. These additives may include: dispersants, viscosifying agents to control filtration, lubricating agents, and numerous other functions for specific compounds (Ferreira [3]).

In hidroargilosos fluid, sodic bentonite clays are used in order to increase the viscosity of the medium and to form the grout, a low permeability layer is formed on the pit wall to prevent losses from filtration. It is known that the bentonite must exhibit a high degree of swelling; a characteristic that is preferably present in the sodium bentonite type (James et al. [4]).

The water-based fluids and bentonite clays are used in most worldwide drilling operations because they are considered environmentally safe, unlike, for example, oil-based fluids. The latter have highly polluting geological formations with which they come in contact during drilling. In Brazil, most clays used in the preparation of drilling fluids are bentonite clays from the municipality of Boa Vista, in the state of Paraíba.

In sensitive contact with water - "offshore" drilling - it is necessary to use oilbased drilling fluids (Mahto and Sharma [5]). In these cases, bentonite clays lose their thixotropic properties, and cannot be used without prior treatment, since their surface becomes hydrophobic, and its natural state is hydrophilic (Silva and Ferreira [6]). After treatment, when hydrophobic organoclay is dispersed in the oleophilic medium, it allows the drilling fluid to become a gelatinous fluid, due to the recovery of its properties.

Brazil stands out in oil exploration in deep water, where oil-based drilling fluids are used. The success of drilling operations, and its cost, fundamentally depend on the quality of drilling fluids, which makes the process of oil production more practical and efficient. Thus, improved rheological properties offer greater efficiency in the activities performed during the drilling process.

Lately, the oil companies in Brazil are importing organoclays in the preparation of drilling fluid-based oil. Thus, the importance of this work is given by the need for studies to obtain national organoclays, which are more affordable, as well as adding value to a national surfactant used in the superficial change of clay.

\section{Materials and methods}

Before the rheological analysis, we use a surfactant to make surface modification. Table 1 illustrates the concentration of surfactant and the term c.m.c means 'critical micellar contraction'.

Table 1: Concentration of the surfactant used in surface modification.

\begin{tabular}{|c|c|c|c|}
\hline Surfactant & Concentration $(\mathrm{g} / \mathrm{mL})$ & Quantity for $500 \mathrm{ml}$ of fluid $(\mathrm{g})$ & Clay $(4.16 \%)$ \\
\hline $30 \%$ above the c.m.c & 0.0027 & 1.35 & 20.8 \\
\hline In c.m.c & 0.0021 & 1.05 & 20.8 \\
\hline $30 \%$ below c.m.c & 0.0015 & 0.75 & 20.8 \\
\hline
\end{tabular}




\section{Rheological analysis}

The rheological analysis aims to determine the affinity of the modified clay as viscosity fluid oil-based. Accordingly, we developed a fluid-based oil to test the modified clay, as per the composition is listed in Table 2. The basis of calculation used was 25 grams.

Table 2: $\quad$ Composition of test fluid.

\begin{tabular}{|l|c|c|}
\hline \multicolumn{1}{|c|}{ Component } & Percent (\%) & Massa (g) \\
\hline $\mathrm{N}-$ paraffin (oil phase) & 60 & 15 \\
\hline RNX -40 (emulsifier) & 30 & 7.5 \\
\hline $\begin{array}{l}\text { Saline solution }- \\
35000 \text { ppm NaCl }\end{array}$ & 10 & 2.5 \\
\hline Viscosity agent (clay) & 2 & 0.5 \\
\hline
\end{tabular}

The Mars rheometer Thermo Scientific was used to determine the plastic viscosity, yield point, and degree of thixotropy. Assays were performed at ambient temperature $\left(26^{\circ} \mathrm{C}\right)$. The plastic viscosity and yield point were determined by varying the shear rate $\left(1-1010 \mathrm{~s}^{-1}\right)$. The degree of thixotropy was determined using the hysteresis cycle, which consists of determining the area between the curves generated by a particular value to increase rate $\left(1010 \mathrm{~s}^{-1}\right)$, kept at this shear rate for a specified time (60 s) until there is a decrease in shear stress (curved back).

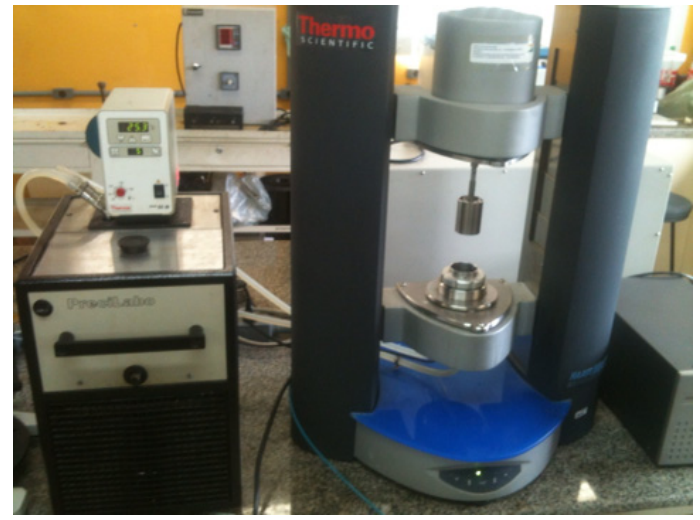

Figure 1: Reometro Mars of Thermo Scientific.

\section{Results and discussion}

Figure 2 show the results of the viscosity of fluids for various shear rates. Regardless of the surfactant concentration used, all results show a behavior of Bingham fluids. In this case, for the fluids which behave as a solid until a minimum voltage, called the yield stress, is exceeded, the relationship between stress and the shear rate becomes linear. 

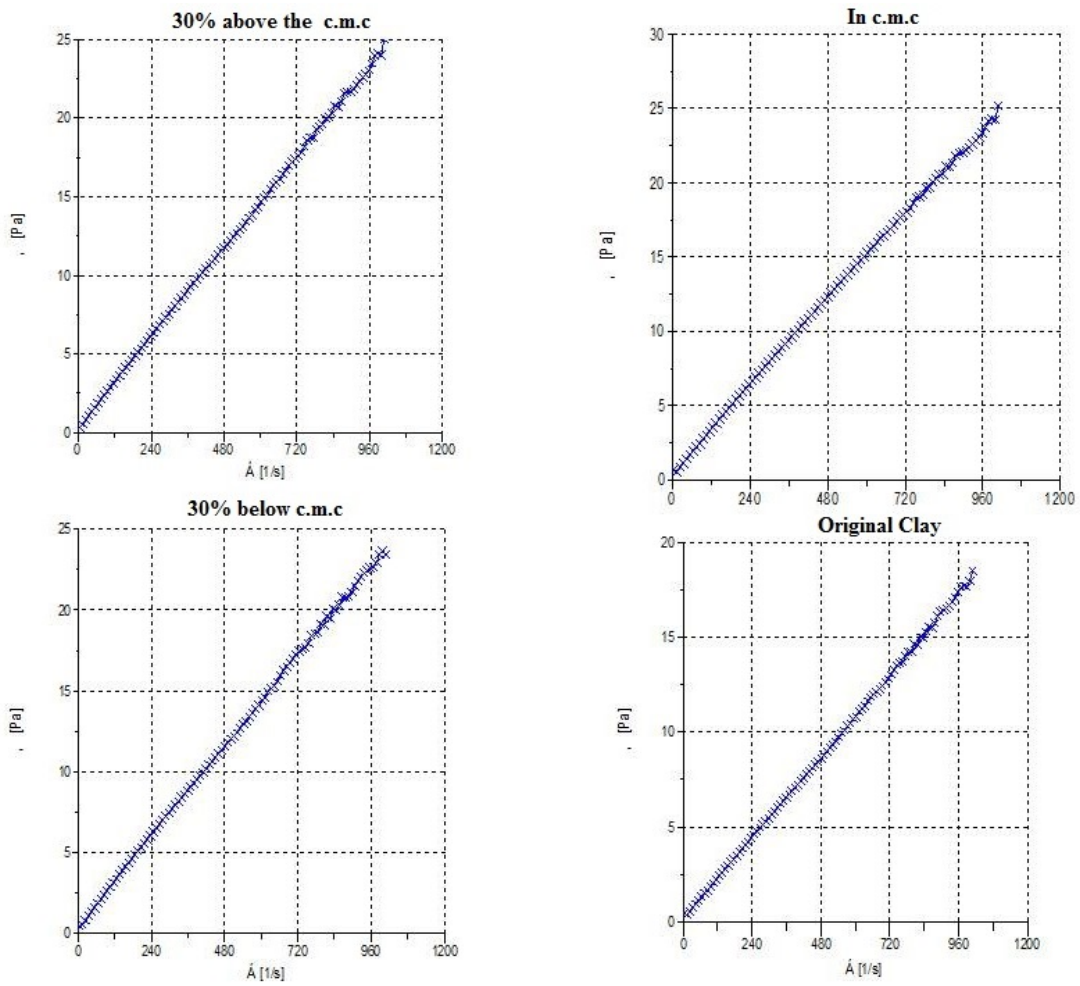

Figure 2: Graphs of viscosity versus shear rate for fluid prepared with the modified clays in various concentrations of surfactant.

Table 3 shows, for the modified clays and the originals, the results of plastic viscosity (VP), which is the proportionality constant between shear stress and shear rate in excess of the yield stress tension. Mathematically, it is the slope of the Bingham model; apparent viscosity (VA) and yield point (LE), which provides the minimum voltage to be applied to the fluid from moving point. Mathematically, it is the linear coefficient of the straight line of the Bingham model.

Table 3: Results for the fluid rheology with modified clay and clay original.

\begin{tabular}{|l|c|c|c|}
\hline \multicolumn{1}{|c|}{ Fluid } & VP $(\mathrm{cP})$ & LE $(\mathrm{cP})$ & VA $(\mathrm{cP})$ \\
\hline $30 \%$ above c.m.c & 24.04 & 0.6627 & 25.60 \\
\hline In c.m.c & 23.83 & 0.3925 & 24.33 \\
\hline $30 \%$ below c.m.c & 23.19 & 0.4768 & 23.90 \\
\hline With original clay & 17.84 & 0.1480 & 17.95 \\
\hline
\end{tabular}

We observed that the viscosity values increased with the amount of surfactant on the clay surface modification process. This is basically due to the fact that when the surfactant is in small quantity, only the training of monomers occurs, which does not occupy the entire surface of the clay, causing its low affinity for oil. As 
we increase the amount of surfactant, micelle formation occurs on the surface of the clay, so that its affinity for the oil phase increases, resulting in higher viscosity of the fluid. Figure 3 illustrates the adsorption of surfactant on the surface of clay.

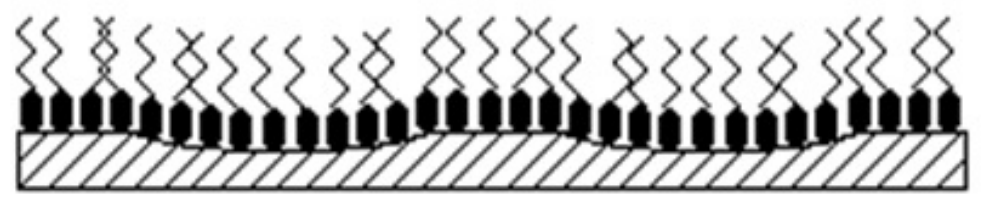

Figure 3: Surfactant being adsorbed onto the clay surface.

\section{Conclusion}

The use of surfactant allows for changing the chemical properties of clays, permitting its applicability in systems that were not previously considered as viable.

The use of surfactant gives good results in the modification of clays and definitions of their new properties when applied in the drilling fluid, suggesting its use in this process.

From the results obtained, we can see that the largest averaged concentration of surfactant in the surface modification process has modified the best performance when applied to oil-based drilling fluid clay.

\section{Acknowledgements}

We thank the PRH-PB221 (PETROBRAS) for financial support and the Center for Primary Processing and Reuse of Produced Water and Waste - NUPPRAR for the possibility of performing the research.

\section{References}

[1] Amorim, L.V., Improvement, Protection and Recovery of Fluid Rheology Hidroargilosos for Use in Drill for Oil, Doctoral Thesis, Federal University of Campina Grande, Campina Grande-PB, 2003.

[2] Amorim, L.V., Theory of Clay, Specialization in Drilling Fluids, 2007.

[3] Ferreira, H.S., Obtaining purified organophilic clays for use in oil-based drilling fluids, dissertation presents the Graduate Program in Materials Science and Engineering, November, 2005.

[4] James, O.O., M. Adediran Mesubi, F.A. Adekola, and Odebunmi, J.I.D. Adekeye. Beneficiation and characterization of a bentonite from north-eastern Nigeria. Journal of the North Carolina Academy of Science. 124(4). 2008, pp. 154-158. 
[5] Mahto, V., Sharma, V.P., Rheological study of a water based oil well drilling fluid, Journal of Petroleum Science and Engineering, 45, pp. 123-128, 2004.

[6] Silva, A.R.V. and Ferreira, H.C., Smectite Organoclays: concepts, structures, properties, uses and industrial producers/suppliers national and international, Electronic Journal of Materials and Processes, Vol. 3.3 (2008) 01-11.

[7] Souza Santos, P., Technology clays, Ed Edgard Blücher, Vol. 3, Sao Paulo, 1992. 